\title{
Inhibition of Epithelial-Mesenchymal Transition and Metastasis by Combined TGFbeta Knockdown and Metformin Treatment in a Canine Mammary Cancer Xenograft Model
}

\author{
Camila Leonel $^{1,2}$ - Thaiz Ferraz Borin ${ }^{2,3}$ - Lívia de Carvalho Ferreira ${ }^{1,2}$ • \\ Marina Gobbe Moschetta ${ }^{2,3}$ - Marcio Chaim Bajgelman ${ }^{4}$ Alicia M. Viloria-Petit ${ }^{5}$. \\ Debora Aparecida Pires de Campos Zuccari ${ }^{1,2}$
}

Received: 22 January 2016 / Accepted: 19 December 2016 / Published online: 11 January 2017

(C) Springer Science+Business Media New York 2017

\begin{abstract}
Epithelial mesenchymal transition (EMT) is a process by which epithelial cells acquire mesenchymal properties, generating metastases. Transforming growth factor beta (TGF- $\beta$ ) is associated with this malignancy by having the ability to induce EMT. Metformin, has been shown to inhibit EMT in breast cancer cells. Based on this evidence we hypothesize that treatment with metformin and the silencing of TGF- $\beta$, inhibits the EMT in cancer cells. Canine metastatic mammary tumor cell line CF41 was stably transduced with a shRNA-lentivirus, reducing expression level of TGF- $\beta 1$. This was combined with metformin treatment, to look at effects on cell migration and the expression of EMT markers. For in vivo study, unmodified or TGF- $\beta 1$ sh cells were injected in the inguinal region of nude athymic female mice followed by metformin treatment. The mice's lungs were collected and metastatic nodules were subsequently assessed for EMT markers expression. The migration rate was lower in
\end{abstract}

Debora Aparecida Pires de Campos Zuccar

debora.zuccari@famerp.br

Camila Leonel

camilaleonels_1@hotmail.com

Thaiz Ferraz Borin

thaiz80@yahoo.com.br

Lívia de Carvalho Ferreira

livinha_ferreira@hotmail.com

Marina Gobbe Moschetta

mary_na15@hotmail.com

Marcio Chaim Bajgelman

marcio.bajgelman@lnbio.cnpem.br

Alicia M. Viloria-Petit

aviloria@uoguelph.ca
TGF- $\beta 1$ sh cells and when combined with metformin treatment. Metformin treatment reduced $\mathrm{N}$-cadherin and increased E-cadherin expression in both CF41 and TGF- $\beta 1$ sh cells. Was demonstrated that metformin treatment reduced the number of lung metastases in animals bearing TGF- $\beta 1$ sh tumors. This paralleled a decreased $\mathrm{N}$-cadherin and vimentin expression, and increased E-cadherin and claudin-7 expression in lung metastases. This study confirms the benefits of TGF- $\beta 1$ silencing in addition to metformin as potential therapeutic agents for breast cancer patients, by blocking EMT process. To the best of our knowledge, we are the first to report metformin treatment in cells with TGF- $\beta 1$ silencing and their effect on EMT.

Keywords Breast cancer $\cdot$ Metastasis $\cdot$ Anticarcinogenic agents $\cdot$ shRNA $\cdot$ TGF- $\beta$
1 Universidade Estadual Paulista "Julio de Mesquita Filho" (UNESP/ IBILCE), PostGraduate Program in Genetics, Cristovao Colombo Street, 2265, Jardim Nazareth, Sao Jose do Rio Preto, SP, Brazil

2 Faculdade de Medicina de Sao Jose do Rio Preto (FAMERP), Laboratory of Molecular Investigation of Cancer (LIMC), Brigadeiro Faria Lima Avenue, 5416, Vila São Pedro, Sao Jose do Rio Preto, SP, Brazil

3 Faculdade de Medicina de Sao Jose do Rio Preto (FAMERP), PostGraduate Program in Health Sciences, Brigadeiro Faria Lima Avenue, 5416, Vila São Pedro, Sao Jose do Rio Preto, SP, Brazil

4 National Center for Research in Energy and Materials - CNPEM, Brazilian Biosciences National Laboratory - LNBio, Giuseppe Máximo Scolfaro Street, Campinas, SP 10000, Brazil

5 Department of Biomedical Sciences, Ontario Veterinary College, University of Guelph, 50 Stone Rd E, Guelph, ON N1G 2W1, Canada 


\section{Introduction}

The high mortality rate in breast cancer is mainly due to metastatic disease. The mechanisms for the occurrence of metastases are variable and require several stages starting with the loss of contact with neighboring cells, following the penetration of the vessel walls, joining the new location and angiogenesis [1].

The migration and invasiveness of epithelial tumor cells has been linked to the re-activation of a developmental process called epithelial-mesenchymal transition (EMT) [2], characterized by the down-regulation of epithelial markers such as claudin, E-cadherin and keratins, loss of apical-basal cell polarity and cell-cell adhesion, and the up-regulation of mesenchymal markers such as N-cadherin and vimentin, as well as the production matrix-degrading enzymes. Altogether, this facilitates migration and invasiveness capacity during the process of malignant transformation, and tumor cell dissemination to surrounding tissues and distant sites [2-4]. EMT can be induced by extracellular matrix components and growth factors, such as transforming growth factor beta (TGF- $\beta$ ) and epidermal growth factor (EGF) [5, 6], which might cooperate with intrinsic transforming events (e.g., oncogenes) to promote mesenchymal phenotypes [7].

TGF- $\beta$ is involved in many physiological processes responsible for regulating cellular differentiation and proliferation, migration and apoptosis. In breast and other epithelial cancers, TGF- $\beta$ is well-documented to have a stagedependent dual role, by acting as a suppressor of proliferation and/or inducer of cell death in early stages of carcinogenesis, but promoting survival, proliferation and invasiveness/ metastasis in advanced stages $[8,9]$. TGF- $\beta$ is a member of the TGF- $\beta$ superfamily comprised of 33 ligands, including bone morphogenic proteins (BMP) and activins. TGF- $\beta$ itself exists in three isoforms, TGF- $\beta 1$, TGF- $\beta 2$ and TGF- $\beta 3$. The signaling of these isoforms is comparable in some settings, and the expression levels varies among different tissues [10]. TGF- $\beta 1$ in particular, is the best documented to play a role in the progression of breast cancer, promoting metastasis in many experimental rodent models. In some of these models, TGF- $\beta$ is supplied by the a tumor cell-dependent tumor microenvironment in the lung $[11,12]$ and bone $[11,13]$.

Stem cells have been investigated for their central role in the development of tissues and organs. Research within the last two decades suggest that cells with stem/progenitor characteristics also play a critical role in tumor initiation and progression [14, 15]. Evidence linking EMT to breast cancer stem cells (BCSCs) was first reported by Mani et al. [16], who showed that the induction of this process in mammary epithelial cells transformed in vitro, generate cells with BCSCs properties.

The definition of the cellular and microenvironmental signals that induce the EMT during the progression of breast cancer is crucial to provide new therapeutic targets in an attempt to avoid metastasis and/or properly manage metastatic disease ro reduce cancer mortality. Currently, intervention tools have been employed to block cellular signaling pathways that induce EMT and subsequent metastasis. These include oncolytic adenoviruses [17], RNA interference [18, 19], and molecular-targeted drugs, such as pharmacological signalling inhibitors [4].

Several other anti-tumor and possibly EMT-targeting approaches have been more recently identified, based on the use of drugs initially intended to treat other conditions. One example of these is metformin, which is used orally to reduce the glucose concentration in the blood of patients with type 2 diabetes and metabolic syndrome, with well-established and manageable side effects and safety profiles. Following epidemiological findings linking the use of metforming to reduced incidence of certain cancers, particularly of the breast [20], this drug has been widely studied for its anti-tumor activities $[21,22]$. Among the mechanims of metformin anti-tumor activity, the activation of AMPK (AMP-activated protein kinase) signaling has been shown to inhibit the mTOR pathway, and several studies showed metformin's capacity to inhibit epithelial-mesenchymal transition (EMT) in human breast cancer cells [23-26]. In support of previous finding linking stemness to EMT [16], Hirsch et al. [27] recently demonstrated that tumor stem cells have a greater sensitivity to metformin, and according to a study by Cufí et al. [28], treatment with metformin suppresses the mesenchymal phenotype by transcriptional repression of key EMT-promoting genes, including (ex. Zinc Finger E-Box Binding Homeobox 1 (ZEB1), TWIST1, SNAIL2/SLUG, and TGF- $\beta$.

Based on the aforementioned findings, this study addressed the possibility that blocking TGF- $\beta$ signalling input and treatment with metformin in a mesenchymal metastatic breast cancer cell line, inhibits the occurrence of metastasis. We show that TGF- $\beta 1$ knockdown by RNA interference in mesenchymal CF41 canine mammary cells potentiates the EMT- and invasiveness-targeting effects of metformin in CF41 in vitro. A pilot animal study suggests enhanced EMT- and metastasissuppressing effects by this combined approach but suggest complex interactions between the two strategies that warrant further invesitigation.

\section{Material and Methods}

This study was approved by the ethics committee on animal use (CEUA) of the Faculty of Medicine of Sao Jose do Rio Preto (FAMERP) \# 3244/2012, which is developed following national and international standards of ethics in animal experimentation.

\section{Antibodies}

Antibodies used in this study were as follows: vimentin (\#M0725) from DAKO (Carpinteria, CA, USA); N-cadherin (\#sc7939) from Santa Cruz Biotechnology (Dallas, Texas, 
USA), E-cadherin (\#3195S) from Cell Signaling Technology (Danvers, Massachusetts, USA), claudin-7 (ab27487) from Abcam (Cambridge, UK) and Alexa-Fluor ${ }^{\circledR}$-conjugated secondary antibodies from Life Technologies (Eugene, OR, USA).

\section{Cell Culture}

The metastatic canine mammary tumor cell line CF41 (ATCC, Manassas, VA, USA) was cultured in $75 \mathrm{~cm}^{2}$ culture flasks (Sarstedt, Nümbrecht, Germany) with Dulbecco's modified Eagle's medium - high glucose (DMEM) (Cultilab, Campinas, SP, Brazil) supplemented with $10 \%$ fetal bovine serum (FBS) (Cultilab, Campinas, SP, Brazil), penicillin (100 IU/ $\mathrm{mL})$ and streptomycin $(10 \mathrm{mg} / \mathrm{mL})$ (Sigma-Aldrich, St. Louis, $\mathrm{MO}$, USA) in a humidified incubator at $5 \% \mathrm{CO}_{2}$ and $37^{\circ} \mathrm{C}$.

\section{Cell Viability by MTT (3-(4,5-Dimethylthiazol-2-Yl) -2,5-Diphenyltetrazolium Bromide) Assay}

For MTT assay, $5 \times 10^{4}$ cells/well were plated in 96-well plates in $100 \mu \mathrm{L}$ DMEM with $2 \%$ FBS. Then cells were treated for $24 \mathrm{~h}$ with different concentrations $(1 \mathrm{mM}, 2 \mathrm{mM}, 3 \mathrm{mM}$ and $5 \mathrm{mM}$ ) of metformin (Sigma-Aldrich, St. Louis, MO, USA) diluted in ultrapure water. Thereafter, $10 \mu \mathrm{L}$ of MTT solution (Vibrant MTT Cell Proliferation Assay Kit, Invitrogen - Life Technologies, Eugene, OR, USA) were added to each well and the plates were incubated at $37^{\circ} \mathrm{C}$ for an additional $4 \mathrm{~h}$. Absorbance was measured at $540 \mathrm{~nm}$ by ELISA plate reader (Thermo Fisher Scientific - Waltham, MA USA). Medium with $2 \%$ FBS was used as background and subtracted from the samples. Cell viability (\%) was calculated for all groups compared to control sample (untreated), and all treatment were performed in triplicate. Dose-response curves were generated and IC50 values was directly calculated from the dose-response curve using equation results of linear regression.

\section{Construction of TGF- $\beta 1$ shRNA-Lentivirus and CF41 Cells Silencing}

We designed shRNA sequences [29] and ordered oligonucleotides encoding shRNA for TGF- $\beta 1$ gene and the GFP control (IDT - USA). The oligonucleotides were then annealed and cloned into the lentiviral transfer plasmid pLKO 1.puro [30]. Recombinant lentivirus were generated by Viral Vector Laboratory at LNBio-CNPEM, specialized in the development of experimental approaches to cancer therapy, based on the supply of inhibitory molecules to tumor cells. CF41 cells were transduced with lentivirus and selected with $2 \mu \mathrm{g} / \mathrm{mL}$ of puromycin (Gibco, Grand Island, NY, USA). Cells were expanded and the knockdown of TGF- $\beta 1$ was confirmed by qPCR. The target sequences selected for TGF- $\beta 1$ shRNA were: forward, $5^{\prime}$ CGG CAC ACT GCA AGT AGA CAT TAA CCT GAC CCA TTA ATG TCT ACT TGC AGT GTG TTT TT -3'; and reverse,
5'-AAT TAA AAA CAC ACT GCA AGT AGA CAT TAA TGG GTC AGG TTA ATG TCT ACT TGC AGT GTG -3'. The same method was used to transduce the negative control virus containing a shRNA against green fluorescent protein (GFP) reporter into cells (GFPsh) to control for the impact of the lentivirus vector into cells.

The annealed oligonucleotides (insert) were ligated to the vector pLKO 1.puro between AgeI (New England Biolabs, Ipswich, MA, USA) and EcoRI (New England Biolabs, Ipswich, MA, USA) restriction sites. After transformation into DH5- $\alpha$ bacteria and selection by ampicillin (Sigma-Aldrich, St. Louis, MO, USA), clones from each insert were selected and checked by sequencing to verify the sequences of interest. QIAquick Gel Extraction Kit (Qiagen, Valencia, CA, USA) and Plasmid Midi Kit (Qiagen, Valencia, CA, USA) was used to extract the plasmidial DNA.

\section{Quantitative RT-PCR}

$T G F-\beta 1, N$-cadherin and E-cadherin gene expression was determined by real-time PCR (qRT-PCR), according to Bustin et al. [31]. Total RNA was extracted from the cultured cells with TRIZOL reagent (Invitrogen - Life Technologies, Eugene, OR, USA). The concentration of RNA from each sample was determined using a NanoDrop 2000 Spectrophotometer (Thermo Fisher Scientific - Waltham, MA, USA). Each sample of total RNA was subjected to reverse transcription using a High Capacity cDNA kit (Applied Biosystems, Foster City, CA, USA).

The qRT-PCR reaction was performed by StepOne Plus Real Time PCR System (Applied Biosystems, Foster City, CA, USA) using inventoried TaqMan assays (Life Technologies, Eugene, OR, USA): $T G F-\beta 1$ (Cf02623325_m1), $N$-cadherin (Cf02696084_m1) and $E$ cadherin (Cf02624269_m1). 40S ribosomal protein S5 (RPS5) and 40S ribosomal protein S19 (RPS19) were used as endogenos control genes to normalized the expression of genes of interest. Primers used for amplification were: RPS5 forward: 5'- TCA CTG GTG AGA ACC CCC TG -3', reverse 5'- GCC TGA TTC ACA CGG CGT A -3', and RPS19 forward 5'- GCC TTC CTC AAA AAG TCT GGG - 3', reverse 5'- GCT TGC TCC CTA CGA TGA GAA C - 3'.

The expression level of genes of interest was determined by relative quantification (RQ) value using the average of normalizing genes $(\Delta \Delta \mathrm{Ct})$. The samples were tested in triplicate and all experiments included a negative control, lacking cDNA.

\section{Migration and Invasion Assay}

The migration and invasiveness of CF4 1 and TGF- $\beta 1$ sh cells were tested with $8 \mu \mathrm{m}$ inserts matrigel-coated membranes in 24 well plates (Becton, Dickinson and Company, Franklin Lakes, NJ, USA). In the upper compartment of the chamber, 
approximately $2.5 \times 10^{4}$ cells/insert were added into culture medium without serum, while $750 \mu \mathrm{L}$ of culture medium (with 10\% FBS) was added to the lower compartment with $5 \mathrm{mM}$ of metformin treatment. For negative and positive controls, $0.5 \%$ and $10 \%$ FBS respectively, were used.

After $24 \mathrm{~h}$, the membranes were washed, fixed in paraformaldehyde, permeabilized in methanol, and stained with hematoxylin to detect the migrated cells. The counting was made with an inverted optic microscope (Nikon Eclipse E200, Melville, NY, USA) and photographed by putting the insert over a plate containing glycerol at $50 \%$. The migration and invasion rate was calculated by dividing the average number of treated cells that migrated and invaded the matrigel membrane by the average of the positive control cells that did so.

\section{N-Cadherin and E-Cadherin Immunofluorescence Staining}

Cells were fixed in $4 \%$ paraformaldehyde solution and permeabilized with $0.5 \%$ triton X-100 (Sigma-Aldrich). The primary antibodies N-cadherin (Santa Cruz Biotechnology) and Ecadherin (Cell Signaling Technology) were used to assess the expression of respective antigens, and the secondary antibody was Alexa Fluor 488 anti-rabbit IgG (Life Technologies). Following secondary antibody, the structures were incubated with 4',6-diamidino-2-phenylindole (DAPI) solution (Life Technologies) and mounted with Prolong Gold (Life Technologies). Nuclei and antigens were visualized with a confocal microscope (ZEISS LSM 710, software ZEN 2010, Thornwood, NY, USA) at 40X objective magnification.

\section{Animal Model}

Athymic nude female mice $(n=30)$ weighing $17.8-19.4 \mathrm{~g}$ were randomly separated into groups of treatment, and kept under pathogen-free conditions at room temperature (21 to $25^{\circ} \mathrm{C}$ ) on exposure to light for $12 \mathrm{~h}$ and $12 \mathrm{~h}$ in the dark. Food and water were offered ad libitum. The mice were purchased from central animal laboratory of medical school of Sao Paulo University (FM-USP).

For primary breast tumor and lung metastasis induction, $3 \times 10^{6}$ viable cells were washed with PBS, resuspended in $0.1 \mathrm{~mL}$ of serum free RPMI 1640 medium (Gibco, Grand Island, NY, USA), and injected into the fourth right inguinal mammary fat pad. Mice were divided according to the following six treatment groups ( $n=5$ animals/group): Group I: animals that were not implanted with tumor cells and were left untreated (negative control), Group II: animals implanted with parental CF41 cells and untreated (positive control), Group III: animals implanted with CF41 cells treated with metformin alone, Group IV: animals implanted with GFPsh cells and untreated (shRNA control), Group V: animals implanted with
TGF- $\beta 1$ sh cells and untreated, Group VI: animals implanted with TGF- $\beta 1$ sh cells and treated with metformin.

After one week of tumor cell implantation, the animals received metformin treatment for 4 weeks. The drug was administered intraperitoenaly (i.p.) at a dose of $200 \mathrm{mg} / \mathrm{kg}$ per day as previously reported [32]. Tumor volume and body weight were measured once a week. Tumor volume was calculated using the formula $\mathrm{V}=$ length $\times$ width $2 / 2$.

\section{Measurement of Blood Glucose of the Experimental Group}

The measurement of blood glucose was performed to verify the glycemic variation and the potential cytotoxicity of metformin in treated animals, as previously reported [32]. A drop of blood was collected using a 26 gauge needle to venipuncture of tail vein of animals, once a week throughout the treatment period. Glucose levels were detected using a standard blood glucose portable apparatus (Abbott Optium Xceed®), with individual reagent strips for rapid determination indicating amounts in milligrams per deciliter ( $\mathrm{mg} / \mathrm{dL})$.

\section{Histopathology and Immunohistochemistry}

After 4 weeks of treatment the animals were euthanized, and perfused with PBS and 4\% paraformaldehyde (Acros Organics, New Jersey, USA). The lungs were collected, fixed in $4 \%$ paraformaldehyde, prepared for paraffin blocks and sectioned. Standard haematoxylin and eosin (H\&E) staining was performed to evaluate the metastases presence and immunohistochemical (IHC) staining procedures were performed as recommended by the suppliers of primary antibodies. The following antibodies were used to delineate the expression of corresponding antigens: $\mathrm{N}$-cadherin (Santa Cruz Biotechnology), E-cadherin (Cell Signaling Technology), claudin-7 (Abcam) and vimentin (Dako).

Briefly, the slides containing lung tissues were deparaffinized, rehydrated, incubated with citrate buffer at $96^{\circ} \mathrm{C}$ for 30 min and blocked with $0.1 \%$ of hydrogen peroxide and $1 \%$ of BSA for $20 \mathrm{~min}$ each. Following this process, sections were incubated with the primary antibody (anti-Ncadherin, anti-E-cadherin, claudin-7 and vimentin) at $4{ }^{\circ} \mathrm{C}$ overnight. Of note, The vimentin antibody did not detect mouse antigen, and was therefore used to identify metastatic colonies in serial sections that were parallely stained for the other antigens. This was restricted to the areas of metastatic colonies. Then, incubated with Starr Trek Universal HRP Detection System kit (Biocare Medical, Concord, CA, USA) containing the secondary antibody (biotinylated anti-mouse, -rabbit, -goat immunoglobulins), peroxidase-streptavidin conjugates, and diaminobenzidine tetrachloride (DAB) chromogenic substrate. At last, all sections were counter stained with haematoxylin, dehydrated and cover slipped with Erv Mount (Easypath, Sao Paulo, SP, Brazil). 


\section{Data Analysis and Statistics}

All results were submitted to descriptive analysis to determine statistical normality. An analysis of variance (ANOVA) was performed, followed by the Bonferroni's test. Values of $p \leq 0.05$ were considered statistically significant. The GraphPadPrism 5 software (GraphPad Software, Inc., San Diego, CA, USA) was used.

\section{Results}

\section{MTT Assay of Cell Viability}

CF41 cell line was subjected to MTT cell viability testing, after $24 \mathrm{~h}$ treatment with increasing doses of metformin. At $5 \mathrm{mM}$ metformin, there was a significant $37 \%$ reduction in cell viability $(63,18 \pm 2104 \%)$ compared to control group $(100,0 \pm 7155 \% ; p<0.05 ;$ Fig. 1$)$. In our data, the $y$-axis value from the equation of the curve, it was (IC50 $=67.68 \%$ ), wherein the correspondent doses nearest was around $5 \mathrm{mM}$ $(63.17 \%)$. Based on these results, the $5 \mathrm{mM}$ concentration was used for all the following studies.

\section{Metformin and TGF- $\beta 1$ shRNA Effect on Cell Migration and Invasion}

Expression of TGF- $\beta 1$ was first assessed in CF41 cells by qRT-PCR (data not shown). This was important to infere the feasibility of using this cell line for our knockdown experiments. Next, CF41 were transduced with the shRNA-lentivirus, confirming TGF- $\beta 1$ knockdown by qPCR. TGF- $\beta 1$ mRNA levels were decreased by TGF- $\beta 1$ sh \#2, \#3 and \#4, but sequence \#3 has shown the best target silencing, compared to the others $(-1149 \pm 0,05634$ a.u.; $p=0.0001)$ [for more details see Appendix Fig. 10].

To verify whether metformin or TGF- $\beta 1$ sh alone or in combination would decrease cell invasive potential, we performed a transwell assay using matrigel-covered membranes (Fig. 2). After $24 \mathrm{~h}$ of metformin treatment, there was a significant decrease $(49,03 \pm 5227 \%)$ in invasion and migration

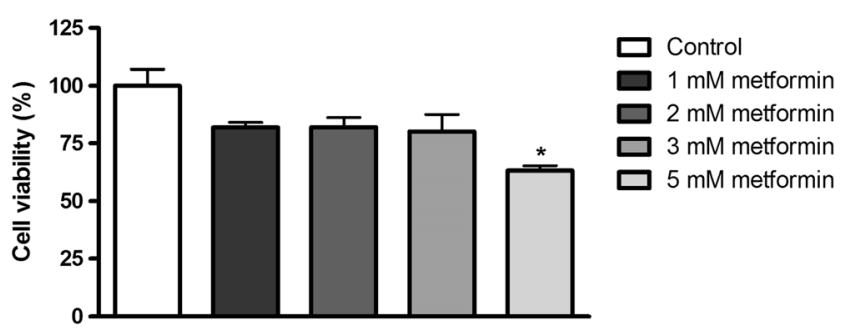

Fig. 1 Effect of metformin on viability of canine mammary tumor cell line. CF41 cells were treated with $1 \mathrm{mM}$ to $5 \mathrm{mM}$ of metformin for $24 \mathrm{~h}$ and cell viability was measured by MTT assay. Significance calculated by ANOVA followed by Bonferroni's test $( \pm$ S.E.M. $* p<0.05)$

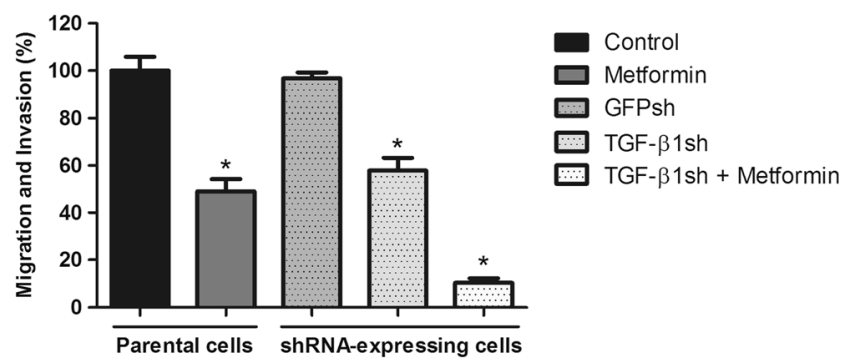

Fig. 2 Cell migration and invasion. Cell migration and invasion assay was carried out in CF41 and TGF- $\beta 1$ sh cells after treatment with $5 \mathrm{mM}$ metformin. Statistically significant differences, verified by ANOVA followed by Bonferroni's test. $* p<0.05$ in comparison to control of untreated parental cells (solid columns) and to control of shRNAexpressing cells (dotted columns)

of CF4 1 cells as compared to positive control $(100,0 \pm 5853 \% ; p=0.0001)$. When compared to GFPsh cells untreated $(96,74 \pm 2542$ a.u.), there was a significant decrease $(57,85 \pm 5394 \% ; p=0.0001)$ in invasion and migration of TGF- $\beta 1$ sh cells and of TGF- $\beta 1$ sh cells treated with metfor$\min (10,48 \pm 1876 \% ; p=0.0001)$. For this assay, the positive control (10\% serum at the bottom well) was used as the basal level to compare to all treatments. The negative control (2\% serum) in this assay showed a $86 \%$ reduction $(13,74 \pm 1195 \%)$ in the migration/invasion of the cells compared to that of positive control $(100,0 \pm 5853 \% ; p=0.0001)$ (data not shown).

\section{N-Cadherin and E-Cadherin Expression after Treatment with Metformin and TGF- $\beta 1$ shRNA}

$\mathrm{N}$-cadherin and E-cadherin are key EMT markers in breast cancer [33]. Therefore, we examined the expression level of these markers to assess possible EMT-suppressing effects of TGF- $\beta 1$ silencing and metformin treatment, alone or in combination.

Treatment with metformin for $24 \mathrm{~h}$ decreased $\mathrm{N}$-cadherin gene and protein expression. Specifcally, we observed a decrease in N-cadherin mRNA expression in parental cells treated with metformin $(-0,1947 \pm 0,03820$ a.u.; $p=0.008)$ compared with positive control $(0,0 \pm 0,0110$ a.u. $)$, and in TGF- $\beta 1$ sh cells and TGF- $\beta 1$ sh cells plus metformin $(-1023 \pm 0,07815$ a.u.; $p=0.0002)$ compared to GFPsh control $(0.0 \pm 0,2077$ a.u.). The protein levels were significantly reduced by the same treatments (metformin, $13,62 \pm 1298$ a.u.; $p=0.0001 ;$ TGF $-\beta 1 \mathrm{sh}$, $11,40 \pm 0,9234$ a.u.; $p=0.0001$ and TGF- $\beta 1$ sh + metformin, $7633 \pm 0,7067$ a.u.; $p=0.0001$ ), compared with respective control groups (Control, 25,97 \pm 2092 a.u.; GFPsh, $25,62 \pm 1966$ a.u.) (Fig. 3). E-cadherin protein expression was higher in CF41 parental cells treated with metformin (9683 $\pm 0,9668$ a.u.; $p=0.0001$ ) compared to untreated control cells (7217 $\pm 0,6032$ a.u.) (Fig. 4). In the TGF- $\beta 1$ silencing cells, E-cadherin expression was significantly higher compared to GFPsh control cells $(8250 \pm 0,9378$ a.u.) at both the 


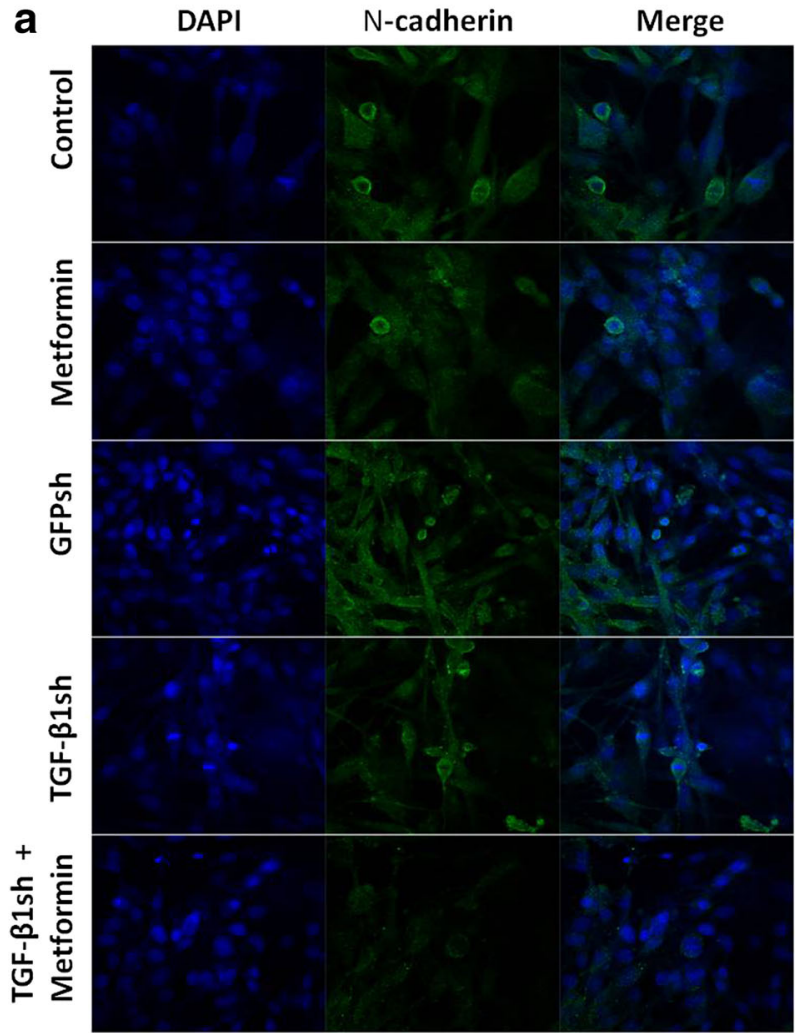

Fig. 3 N-cadherin expression in CF41 cell line. a Photomicrographs of immunofluorescence (IF) staining for $\mathrm{N}$-cadherin (green) and Dapi (blue) in CF41 and TGF- $\beta 1$ sh cells treated with metformin. ZEISS, 2014, 40X. b Plotted results of immunofluorescence quantification. c Gene expression of $\mathrm{N}$-cadherin after treatment, compared to control of

protein $(13,78 \pm 0,9415$ a.u.; $p=0.03)$ and RNA level. Interestingly, when TGF- $\beta 1$ silenced cells were treated with metformin, E-cadherin expression levels ( $6500 \pm 0,6362$ a.u.; $p=0.0001)$ returned to GFPsh control levels $(8250 \pm$ 0,9378 a.u.) (Fig. 4).

\section{Effects of Metformin and TGF- $\beta 1$ Silencing in Animal Model of Breast Cancer Metastasis}

To determine the impact of combined metformin and TGF- $\beta 1$ shRNA intervention in metastasis, we employed a CF41 mouse xenograft model of breast cancer metastasis to the lung. All mice remained healthy during the experiment and no clinical or pathologic signs of metformin treatment were found. All groups had weight changes, however, no changes were significant between the treated groups and the control group $(p>0.05)$ [for more details see Appendix Fig. 11]. After a week of tumor cell implantation, all groups were assessed weekly for blood glucose levels. The animals from the negative control group, who received no tumor induction, presented the same glycemic variation that animals treated with metformin, and the other evaluated groups $(p>0.05)$ [for more b

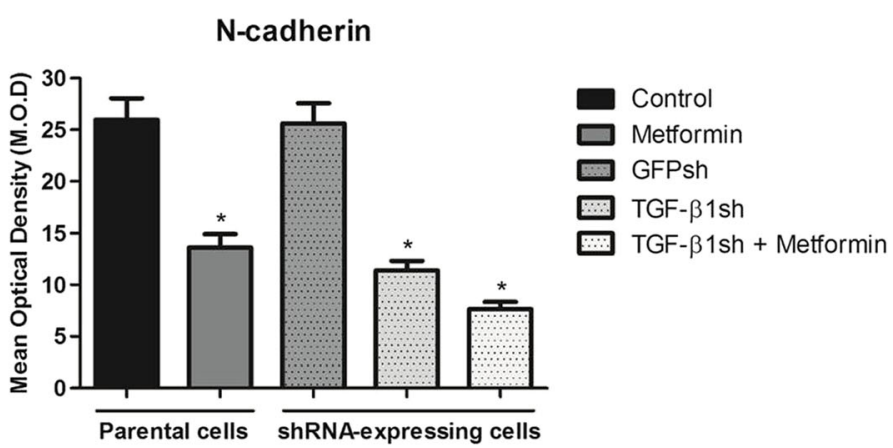

C

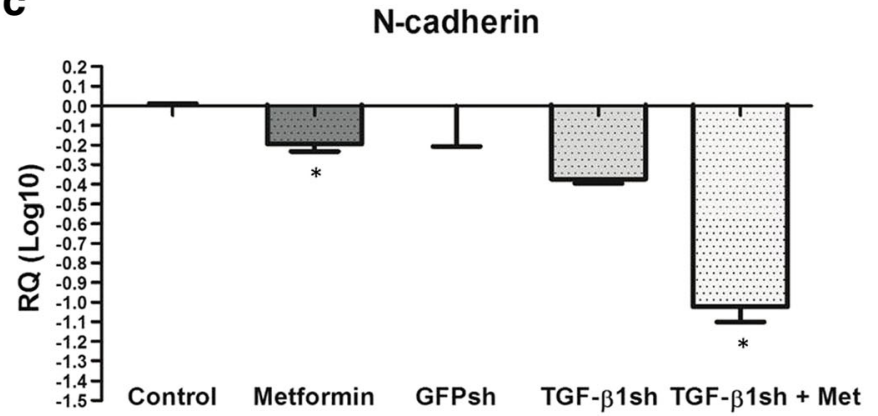

untreated parental cells and control of shRNA-expressing cells, respectively. Each column is the mean \pm standard error of triplicates. Significant values from ANOVA followed by Bonferroni's test ( \pm S.E.M. $* p<0.05$ )

details see Appendix Fig. 12]. In addition, behavioral indicators such as drowsiness or agitation were not observed.

The animals received metformin treatment from the second week of tumor cell implantation, and the results of first week showed that tumor growth was random in the animals of all groups. There was a gradual growth of the primary tumor in the breast region in all groups implanted with tumor cells after 5 weeks, except GFPsh control group, which showed an absolute regression of the tumor size in all animals after the third week of monitoring relative to first week of parental untreated cells $(p=0.001)$ [for more details see Appendix Fig. 13]. As shown in Fig. 5, animals of the group treated with metformin has less metastasis (1000 $\pm 0,3162$ a.u.) compared to control group (4800 $\pm 0,9695$ a.u.; $p=0.005$ ). For the GFPsh control group, although no specific gene silencing is expected in these tumors, we noted that they displayed reduced tumor growth [for more details see Appendix Fig. 13] and a reduced incidence and number of metastasis ( $20 \%$ and $30 \%$, respectively) as compared to the untreated control (parental cells) group (Fig. 5), although no statistically significant differences in the number of metastasis/lung were observed (Fig. 5). It was observed that tumor size is inverse to the number of metastases found. TGF- $\beta 1$ sh group treated with metformin or not it 


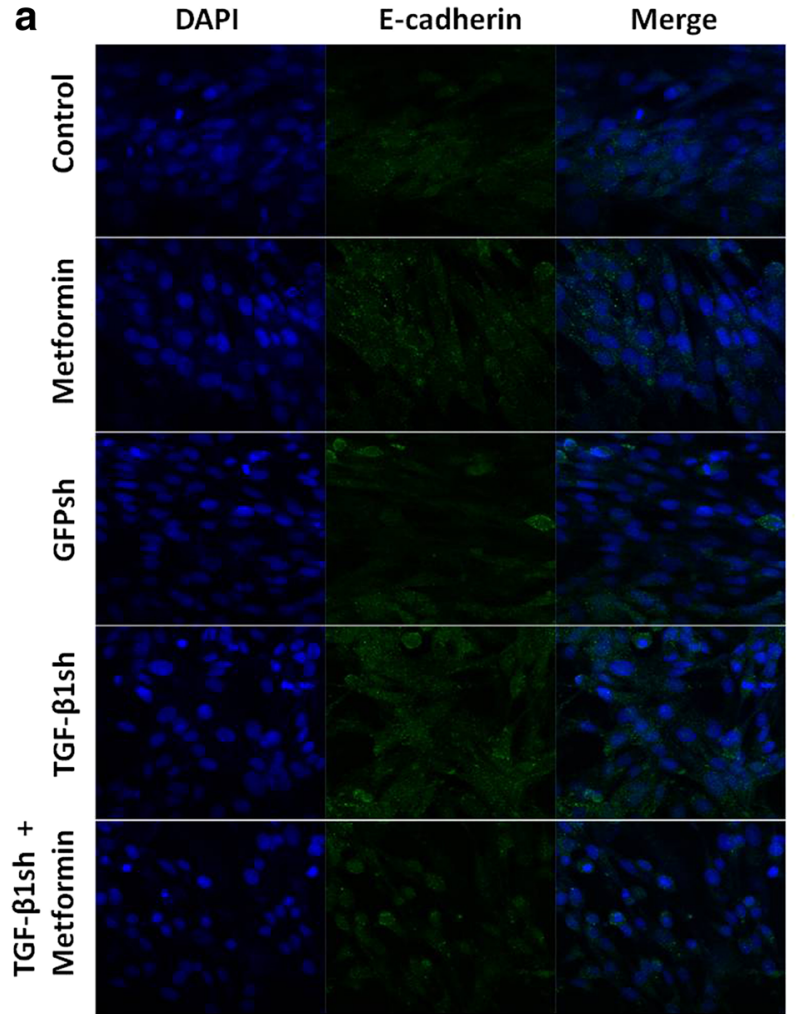

Fig. 4 E-cadherin expression in CF41 cell line. a Photomicrographs of immunofluorescence (IF) staining for E-cadherin (green) and Dapi (blue) in CF41 and TGF- $\beta 1$ sh cells treated with metformin. ZEISS, 2014, 40X. b Plotted results of immunofluorescence quantification. c Gene b
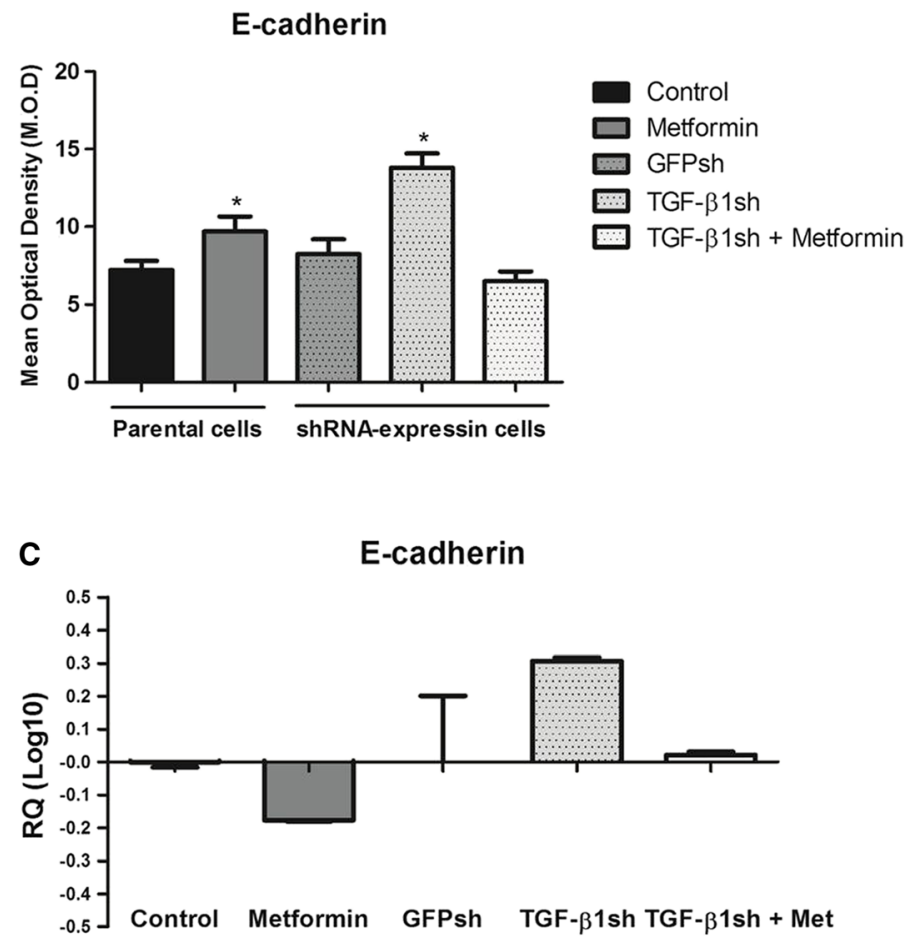

expression of E-cadherin after treatment, compared to control of untreated parental cells and control of shRNA-expressing cells, respectively. Each column is the mean \pm standard error of triplicates. Significant values from ANOVA followed by Bonferroni's test $(( \pm$ S.E.M. $* p<0.05)$ a

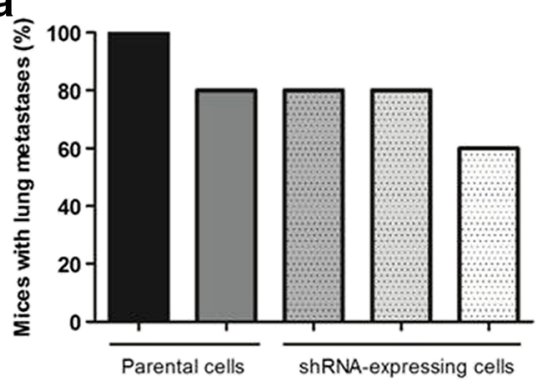

b

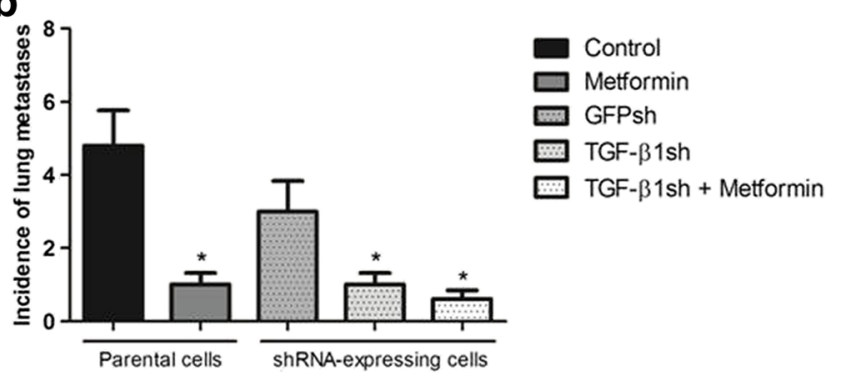

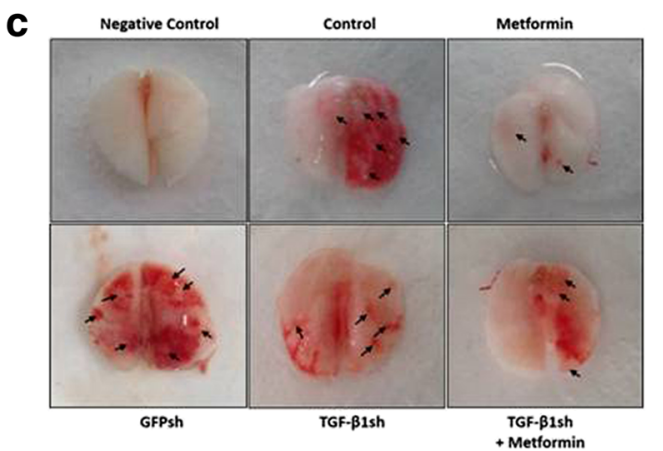

Fig. 5 Analysis of lung metastasis in animal model. a Percentage of mice who had metastasis in each group. b Incidence of metastases in the lungs of mice in each group. Statistically significant differences, verified by
ANOVA followed by Bonferroni's test. $* p<0.05$ in comparison with control of untreated parental cells and control of shRNA-expressing cells. c Macroscopic lung metastasis. Arrows indicate sites of lung metastasis 
was observed higher primary tumor size [for more details see Appendix Fig. 13] and less pulmonary metastass in both, the TGF- $\beta 1$ sh group $(1000 \pm 0,3162$ a.u.; $p=0.05)$ and TGF- $\beta 1 \mathrm{sh}$ group treated with metformin $(0,6000 \pm 0,2449$ a.u. $)$ compared to GFPsh control group $(3000 \pm 0,8367$ a.u.; $p=0.02)$ (Fig. 5). However, CF41 was shown to be a highly metastatic canine mammary tumor cell line when implanted in athymic nude mice and these animals had smaller tumor size, compared to TGF- $\beta 1$ sh and TGF- $\beta 1$ sh treated with metformin groups.

For analysis of protein markers associated to EMT (Ncadherin, E-cadherin, vimentin, and claudin-7) in lung metastatic colonies, IHC was performed, followed by densitometry quantification.

The presence of N-cadherin was observed in lung metastases from all groups, with lesser intensity in the groups treated with metformin and with TGF- $\beta 1$ sh cells. Animals implanted with CF41 cells and treated with metformin showed a significant reduction in protein expression of $\mathrm{N}$-cadherin $(106,7 \pm 1307$ a.u.) when compared to the control group $(154,1 \pm 1817$ a.u.; $p=0.0001))$. The animals implanted with TGF- $\beta 1$ sh cells $(108,1 \pm 0,8859$ a.u.; $p=0.0001)$ and TGF- $\beta 1$ sh cells plus subsequent metformin treatment $(104,8 \pm 1049$ a.u.; $p=0.0001)$ also showed a statistically significant reduction in $\mathrm{N}$-cadherin expression in the lungs compared to GFPsh group (140,7 \pm 1853 a.u.) (Fig. 6).

E-cadherin had increased expression in the lung metastatic lesion of the animals implanted with parental cells and treated with metformin (155,4 \pm 1577 a.u.), compared to the lungs of untreated animals $(105,3 \pm 1383$ a.u.; $p=0.0001)$. A similar effect was seenin the animals implanted with with TGF- $\beta 1$ sh cells in the absence $(139,0 \pm 1776$ a.u.; $p=0.0001)$ or after metformin treatment $(143,4 \pm 2013$ a.u.; $p=0.0001)$, as compared to the GFPsh group (114,6 \pm 1623 a.u.) (Fig. 7).

Treatment with metformin reduced vimentin expression in lung metastatic colonies (126,3 \pm 1378 a.u.) as compared to those formed by control, untreated parental cells $(166,5 \pm 1392$ a.u.; $p=0.0001)$. Similar results were observed for the TGF- $\beta 1$ sh $(118,5 \pm 1408$ a.u.; $p=0.0001)$ and TGF- $\beta 1$ sh plusmetformin groups (114,0 \pm 1606 a.u.; $p=0.0001$ ), in relation to GFPsh group (166,6 \pm 1895 a.u.) (Fig. 8).

Animals treated with metformin had a statistically significant increase in protein expression of claudin-7 (131,5 \pm 1775 a.u.) compared to the positive control group (116,3 \pm 1326 a.u.; $p=0.0001$ ). Similarly, animals transfected with TGF- $\beta 1$ sh cells and treated with metformin had increased protein expression relative to GFPsh control group (131,0 \pm 1786 a.u.; $p=0.008$ ) (Fig. 9).
Fig. $6 \mathrm{~N}$-cadherin protein expression. a Semi-quantitative analysis of $\mathrm{N}$-cadherin protein expression by densitometry in metastatic colonies. b N-cadherin immunostaining in the lungs. Statistically significant differences, verified by ANOVA followed by Bonferroni's test. * $p<0.05$ in comparison with control of untreated parental cells and control of shRNA-expressing

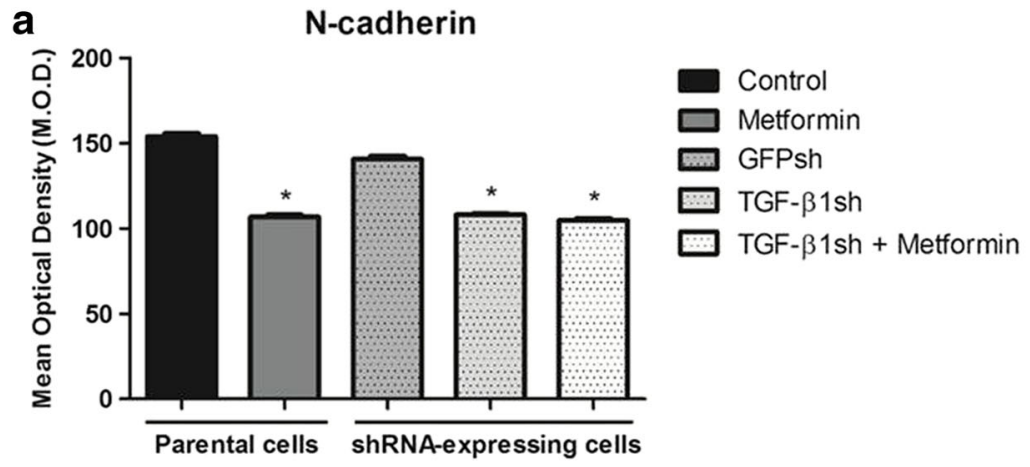

b

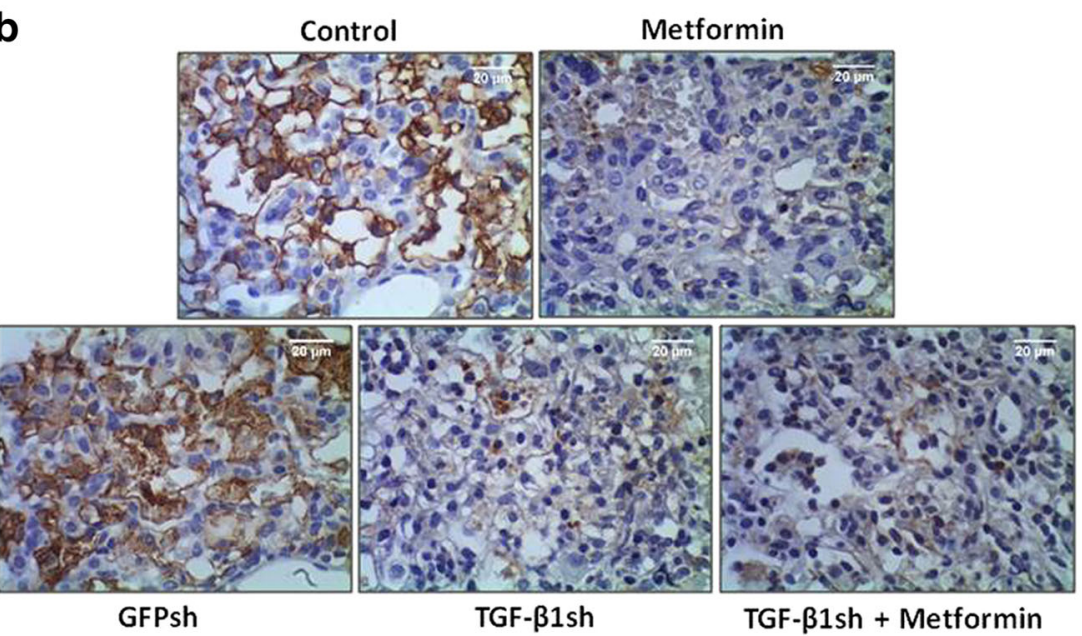


Fig. 7 E-cadherin protein expression. a Semi-quantitative analysis of E-cadherin protein expression by densitometry in metastatic colonies. b E-cadherin immunostaining in the lungs. Statistically significant differences, verified by ANOVA followed by Bonferroni's test. * $p<0.05$ in comparison with control of untreated parental cells and control of shRNA-expressing
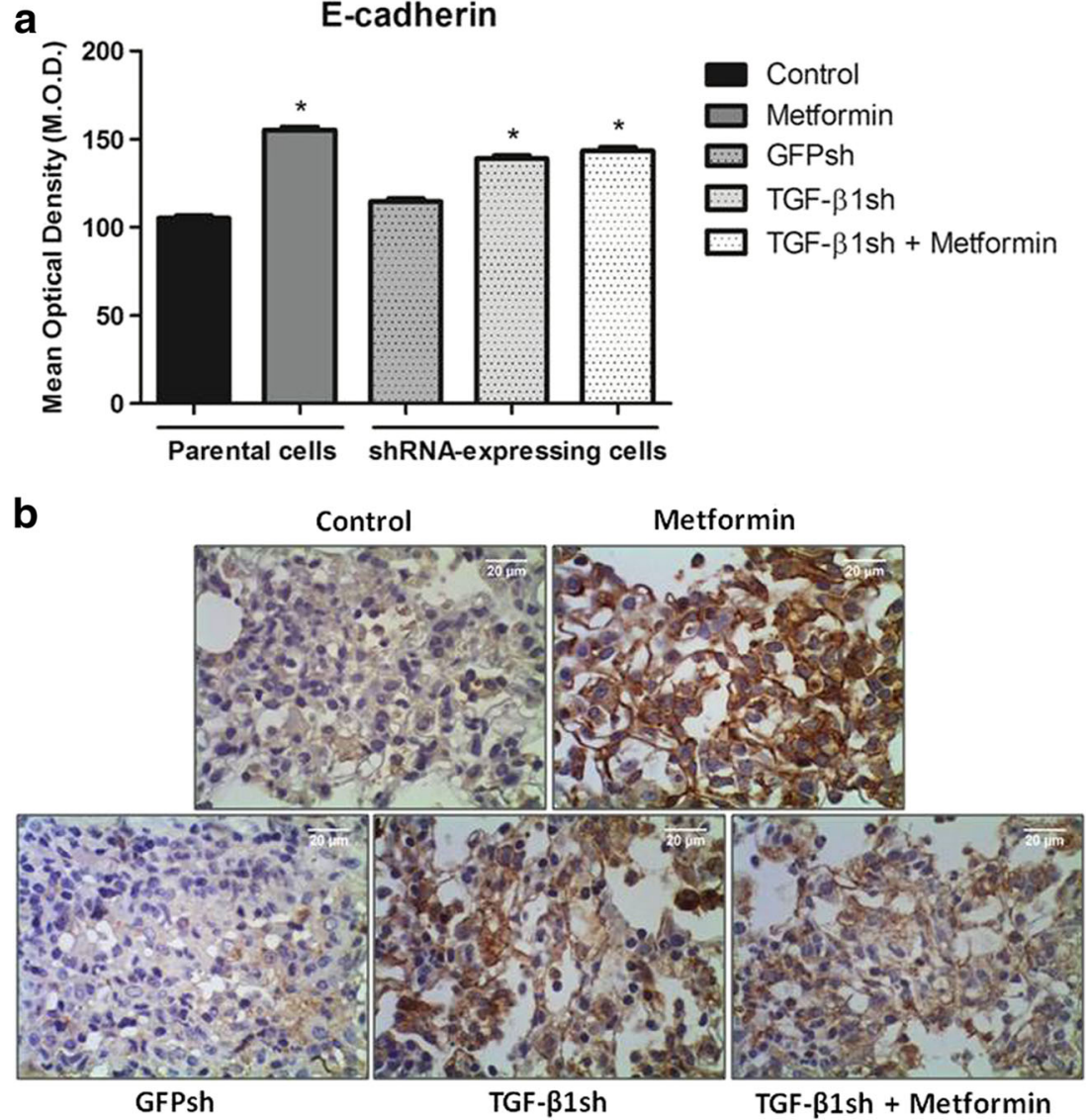

\section{Discussion}

Mean metformin IC50 values obtained in our experiments was about $5 \mathrm{mM}$, ranging from 1 to $10 \mathrm{mM}$ in CF41 cells. Metformin concentrations used in this study were selected according to previous studies which showed that concentrations higher than $10 \mathrm{mM}$ were cytotoxic to cells from various tumor types and that lower doses had excellent results in cell viability, cell migration and invasion. Hirsch et al. [27] showed that metformin at $0.1-0.3 \mathrm{mM}$ could inhibit morphological transformation and invasive growth in breast cancer cells having selectively ability to kill cancer stem cells, and also higher doses as 10 $30 \mathrm{mM}$ are toxic for non-transformed human mammary epithelial cells (MCF-10A). Hwang and Jeong [34], determined the effect of metformin at $5 \mathrm{mM}$ on tumor invasion and migration on fibrosarcoma cells. Cufi et al. [28] in their review showed in MCF-7 and MDCK (canine kidney) cells treated with $1 \mathrm{mM}$ was able to decrease EMT markers and cell proliferation. Cerezo et al. [35] also showed that metformin could dramatically impairs the melanoma tumors growth, migration and invasion in vitro using 5 and $10 \mathrm{mM}$. Zhang et al. [36] demonstrated that metformin at $5 \mathrm{mM}$ significantly inhibited the proliferation and TGF beta EMT induction of prostate cancer cells at 48 and $72 \mathrm{~h}$. Recently, Saeki et al. [37] demonstrated that canine mammary gland tumors cells are sensitive at the concentrations of $2.2 \mathrm{mM}$ up to $20 \mathrm{mM}$, where in metastatic cells shows around $50 \%$ of susceptibility to treatment at $5 \mathrm{mM}$ after $24 \mathrm{~h}$ of metformin, corroborating with our study. In another recent study, Barbieri et al. [38] demonstrated that the concentration of 1 up to $10 \mathrm{mM}$ of metformin caused a significant reduction of cell viability, in a dose-dependent manner, in canine mammary carcinoma stem cells cultures. However, using higher concentrations $(20 \mathrm{mM})$ growth recovery was minimal after $24 \mathrm{~h}$ of treatment, and completely abolished after $48 \mathrm{~h}$, indicating a cytotoxic activity.

In in vivo study, the dosage of $200 \mathrm{mg} / \mathrm{kg}$ of metformin was defined according to the study of Rattan et al. [32] that used A2780 ovarian cancer cells injected intraperitoneally in nude mice and when treated with metformin in drinking water, resulted in a significant reduction of tumor growth, accompanied by inhibition of tumor cell proliferation as well as decreased live tumor size and mitotic cell count. In another study, Kisfalvi et al. [39] observed that maximal inhibitory effect on the increase in tumor volume ( $80 \%)$ of PANC-1 (pancreact carcinoma) tumor xenografts was achieved by administration of metformin at $200 \mathrm{mg} / \mathrm{kg}$.

EMT is well-documented to mediate the process of metastasis, particularly in breast cancer [40]. Developing strategies to maximize inhibiton of EMT to halt cancer progression has high potential to translate into patient benefit. In the present study, treatment with metformin in vitro was able to decrease 
Fig. 8 Vimentin protein expression. a Semi-quantitative analysis of vimentin protein expression by densitometry in metastatic colonies. b Vimentin immunostaining in the lungs. Statistically significant differences, verified by ANOVA followed by Bonferroni's test. * $p<0.05$ in comparison with control of untreated parental cells and control of shRNA-expressing

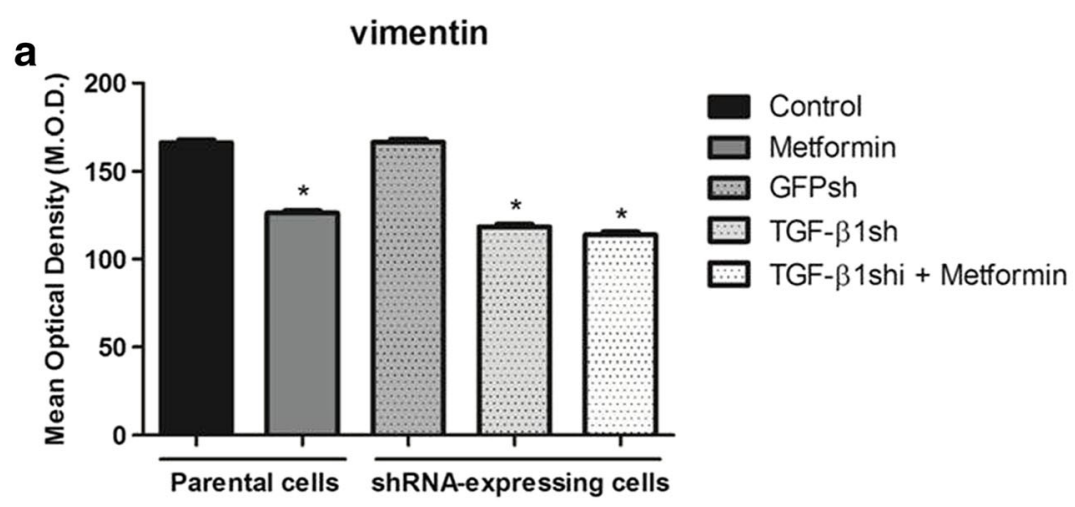

b

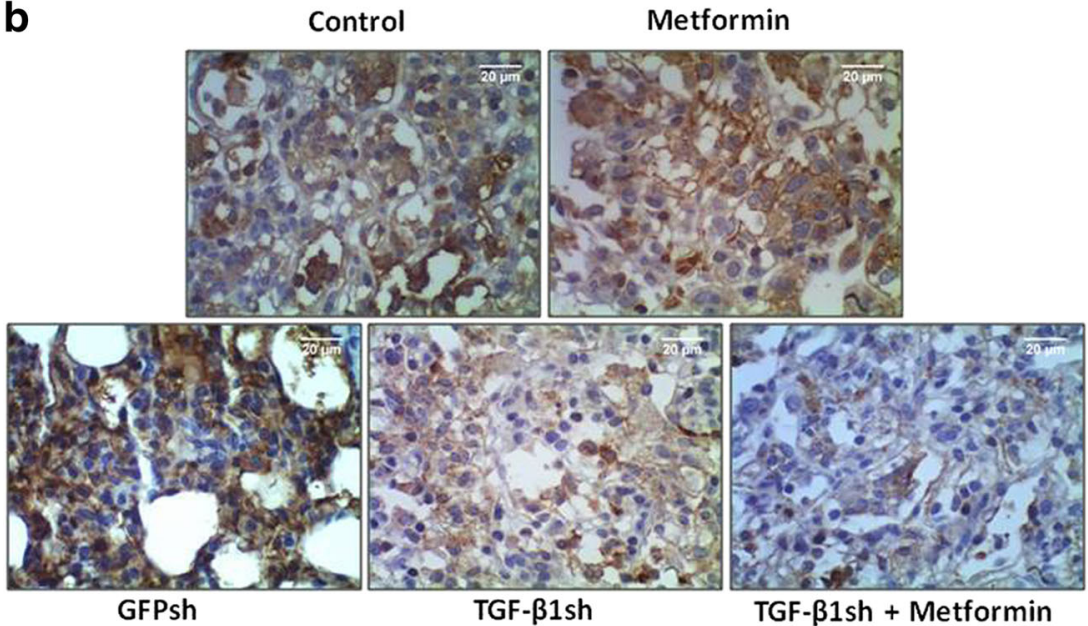

Metformin the viability of the mesenchymal/metastatic CF41 cell line, as well as their rate of migration and invasion. Furthermore, as expected [4], metformin reduced mesenchymal marker expression $\mathrm{N}$-cadherin and increased the expression of the epithelial marker E-cadherin.

There are few studies that demonstrate the action of metformin on EMT. In accordance with our results, Qu et al. [25] demonstrated that metformin reversed the EMT phenotype and decreased invasiveness of human breast cancer cell lines MDA-MB-231 and MCF-7. Further, Cerezo et al. [35] demonstrated that metformin was able to inhibit cell invasion of melanoma cell lines, while Hwang and Jeong [34] showed antimetastatic action of metformin in fibrosarcoma cells, inhibiting cell migration and invasion.

Several mechanisms of antitumor action of metformin have been described, especially a direct effect on AMPK activation, which results in inhibition of mTOR signaling pathway [36]. It has been demonstrated that AMPK activation inhibits EMT induced by TGF- $\beta$ in breast cancer cells [28]. Of the aforementioned, $\mathrm{Qu}$ et al. [25] study demonstrated that treatment with metformin activated AMPK signaling pathway in estrogen receptor positive $(\mathrm{ER}+)$ breast tumor cells that were chemoresistant to 5-fluorouracil (MCF-7/5-FU), as well as triple-negative MDA-MB-231, reversing the multidrug resistant phenotype beyond effects on the EMT process. Metformin also targets other pathways associated with EMT, such as mTOR signaling pathway-S6 K. The high expression of the tyrosine kinase p70S6 $\mathrm{K}$ has been associated to low expression of $\mathrm{E}$ cadherin and high expression of $\mathrm{N}$-cadherin and vimentin. Thus, treatment with metformin inhibits the mTOR-S6 K pathway, and this could also be one possible mechanism by which metformin inhibits EMT and metastasis [41, 42].

Several signaling pathways resulting from the activity of different growth factors are involved in the EMT process, especially TGF- $\beta$ signalling [43]. Thus, given the importance of TGF- $\beta 1$ in the induction of EMT, and the tendency of tumor cells to activate this pathway in an autocrine fashion by secreting their own TGF- $\beta$, the present study focused on gene silencing of TGF- $\beta 1$ in the mesenchymal and metastatic CF41 cell line. As expected, the in vitro results showed that silencing of TGF- $\beta 1$ inhibited cell migration and invasion, and there was a greater reduction with the addition of metformin to gene silencing, suggesting cooperativity of treatments in most experiments. Similar to our results, Moore et al. [18], using metastatic human mammary tumor cells, demonstrated that TGF- $\beta 1$ silencing by RNAi led to a decrease of $35 \%$ of cell migration and $55 \%$ of cell invasion.

Analyzes of mRNA and protein expression in vitro and in vivo studies demonstrated that silencing of TGF- $\beta 1$ resulted in reduction of the mesenchymal markers $\mathrm{N}$-cadherin and 
Fig. 9 Claudin-7 protein expression. a Semi-quantitative analysis of claudin-7 protein expression by densitometry in metastatic colonies. b claudin-7 immunostaining in the lungs. Statistically significant differences, verified by ANOVA followed by Bonferroni's test. * $p<0.05$ in comparison with control of untreated parental cells and control of shRNA-expressing

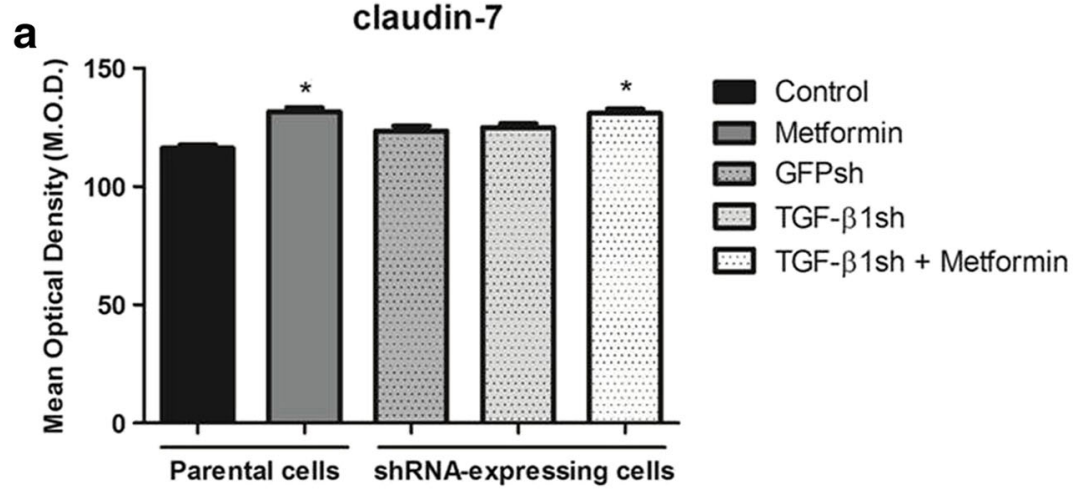

b

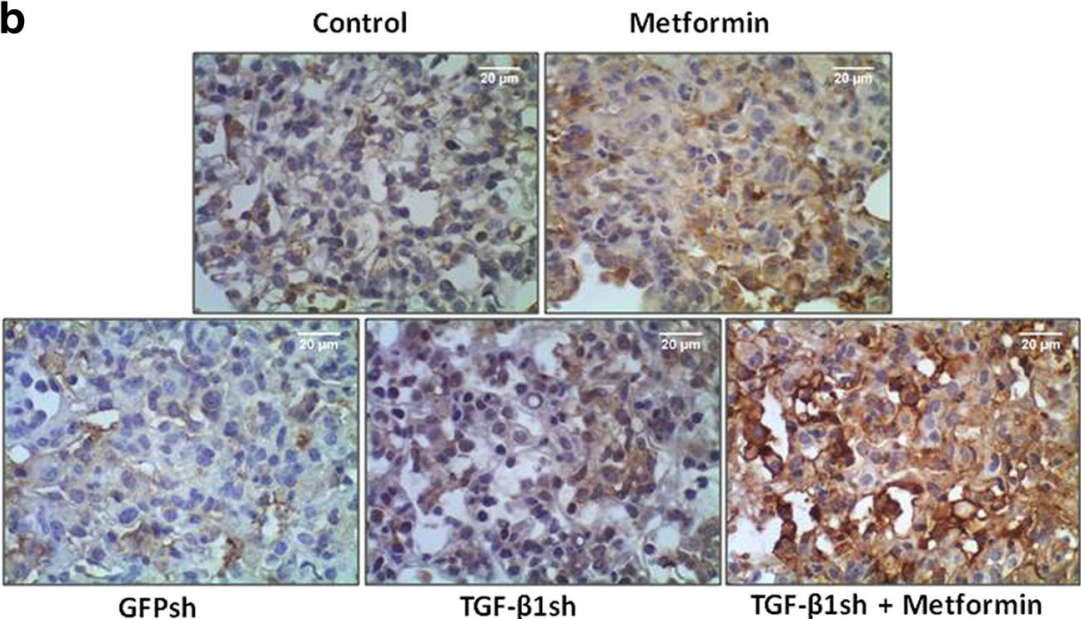

vimentin and enhanced expression of the epithelial markers Ecadherin and Claudin-7, and was equally or more effective in addition to metformin. To the best of our knowledge, this is the first study to investigate the combined action of TGF- $\beta 1$ silencing and metformin treatment. Zhang et al. [36] demonstrated that in vitro treatment with metformin inhibited EMT process induced by TGF- $\beta 1$ in human prostate cancer cells, reducing the gene and protein expression of $\mathrm{N}$-cadherin and vimentin, and increasing the expression of E-cadherin and $\beta$ - catenin.

Our in vivo study found that there were fewer mice with lung metastases and fewer metastastic colonies/lung in animals that received cells with TGF- $\beta 1$ silenced or animals that were treated with metformin, as compared to untreated parental cells. The effect was further enhanced by combined TGF- $\beta 1$ silencing and metformin treatment, and was significant as compared to animals implanted with shRNA control cells. Our in vivo results with TGF- $\beta 1$ silencing alone are in agreement with a previous study by Moore et al. [18] using a mouse xenograft model of metastatic MDA-MB-435 human breast cancer cells, where a $90 \%$ reduction in the number of macroscopic lung metastases was observed in the TGF- $\beta 1$ shRNA group compared to the control group. Further, the increased tumor growth by TGF $\beta$ silencing is also in agreement with the previously reported dual function of this factor in breast cancer, whereby it can simultaneously act as a primary tumor supressor and metastasis inducer, as initially observed in seminal studies by Dr. Massague's [44] group. Others studies support a model, in which TGF- $\beta 1$ inhibits the development of early, benign lesions, but when the tumor suppressor activity is overridden by oncogenic mutations in other pathways, promotes invasion and metastasis $[43,45$, 46]. Studies suggest that expression of the TGF $\beta$ type II receptor (T $\beta$ RII) in breast cancer cells prevents tumor formation [47], while inactivating mutations or overexpression of a dominant negative form of the receptor abolish TGF $\beta$ tumor suppressive effects and increase tumorigenicity [48]. Moreover, low expression levels of T $\beta$ RII are correlated with more advanced and aggressive tumor stages, suggesting that the TGF $\beta$ signaling pathway acts as a tumor suppressor in the early stages of tumor development $[49,50]$.

Relative to tumor size, there was a gradual growth of the primary tumor in the breast region in all groups implanted with tumor cells after 5 weeks, except GFPsh control group, which showed an absolute regression of the tumor size in all animals after the third week of monitoring relative to first week of parental untreated cells. Supposedly, when GFP-reporter gene was transfected into metastatic CF41 cells, there was a selection of these cells due transfection method and also by the use of antibiotics to select the transfected positive cells and this process may have caused the survival only in resistant cells and thus 
more aggressive and metastatic compared to the total population of unmodified cells. This selection made these modified cells more aggressive and more resistant, therefore, increasing the metastatic capacity compared to unmodified cells, as a result, decreased primary tumor size and increased metastatic sites. In contrast, the cells which had the modification to inhibit TGF- $\beta 1$, showed greater primary tumor size due inhibit the aggressiveness of these cells, showing also a decrease of the migratory capacity, highlighting again the importance of the inhibition of TGF- $\beta 1$ in this type of metastatic cells. Meanwhile, metastatic cells CF41 unmodified, had maintained their aggressiveness, because TGF- $\beta 1$ was not inhibited, thus showing tumor growth and metastatic potential, as expected.

Relative to tumor size in vivo after treatment with metformin, Wang et al. [51], demonstrated that xenograft tumor from lung adenocarcinoma A549 cells treated with metformin $(200 \mathrm{mg} / \mathrm{kg} /$ day) was signifiantly decreased in size. The same was observed in a study of Tsutsumi et al. [52] that showed a tumor volume significantly decreased after treatment with metformin compared with the control in animal xenografic model with prostate cancer cell line LNCaP. On the other hand, Lipner et al. [53] demonstrated that metformin does not inhibit growth of patient-derived xenograft (PDX) tumors. No tumor growth inhibition or regression was seen in any of the four PDX tumor lines (Capan-2, CFPAC-1, HPAF-II, and SW1990) at any time point measured and tumor architecture remained grossly unchanged following 28 days of treatment as assessed by hematoxylin and eosin staining.

Our findings with metformin treatment also support previous results. The addition of metformin to conventional chemotherapy was observed to inhibit tumor progression and delay relapse in animal models of breast, prostate and lung cancer [32], and Zhang et al. [54] observed that patients with colorectal cancer and type 2 diabetes treated with metformin showed a significantly reduced rate of distant metastasis compared to the untreated group. A study of Rattan et al. [32] demonstred with A2780 ovarian cancer cells injected intraperitoneally in nude mice that significant pulmonary metastasis was seen in the lungs of untreated mice but not in metformin-treated mice.

Interestingly, although we observed a significantly enhanced in vitro effect of combined TGF- $\beta 1$ sh and metformin as compared to each treatment alone, with relation to viability, invasiveness and EMT markers, the combined treatment was better that each treatment alone at reverting EMT features. It is possible that other factors produced by the tumor stroma (including TGF- $\beta 1$ it self) also induce EMT and metformin treatment does not have the capacity to fully inhibit this in addition to the EMTpromoting effect of tumor cell-derived TGF- $\beta 1$. In this regard, combining metforming with a TGF- $\beta 1$ blocking antibody that targets both the cell autonomous and the stromal tumor compartments might be more effective at maximizing the EMT inhibitory effect. More importantly, this will be more feasible in actual patients, as antibodies of this kind has already demonstrated safety in clinical trials $[55,56]$. Based on the divergence between these and our in vitro findings, one possibility is that metformin treatment in vivo promotes stromadependent compensatory mechanisms that yield TGF- $\beta 1$ silencing at the tumor cell compartment not only ineffective at halting, but possibly more permissive of, lung colonization. Alternatively, and based on recent evidence of the involvenmnet of a mesenchymal-to-epithelial reversion in metastatic colonization $[4,5,57,58]$, it is also possible that excessive rescuing of an epithelial phenotype might in part promote lung colonization. We are currently investigating these possibilities.

\section{Conclusion}

The present study proved the efficacy of metformin at significantly reducing cell viability of the mesenchymal, metastatic CF41 cells. Either metformin treatment or TGF- $\beta 1$ silencing in CF41cells resulted in enhanced expression of epithelial markers and decreased expression of mesenchymal markers, as well as inhibition of invasiveness and metastases, and the combination of the two approaches was more effective that each treatment alone in vitro and in vivo. Our data suggests that therapies combining TGF- $\beta 1$ targeting and metformin may be effective in reducing the process of EMT and metastatic potential. Further studies are necessary to improve our understanding of metformin's effect on the tumor microenvironment in vivo, as to be able to design an approach that exploits these findings more effectively.

ATCC, American type culture collection; BSA, Bovine Serum Albumin; cDNA, Complementary DNA; TGF- $\beta 1$ sh, Small hairpin RNA constructs targeting TGF- $\beta 1$ in CF41 cells; DMEM, Dulbecco's modified Eagle's medium; EMT, epithelial-mesenchymal transition; FBS, fetal bovine serum; GFPsh, green fluorescent protein reporter into CF41 cells; H\&E, Haematoxylin and eosin; MTT, 3-(4,5Dimethylthiazol-2-yl)-2,5-diphenyltetrazolium bromide; PBS, Phosphate buffered saline; qRT-PCR, Real time polymerase chain reaction; RNA, Ribonucleic acid; RPS5, Ribosomal Protein S5; RPS19, Ribosomal Protein S19; TBS-T, Tris-Buffered Saline and Tween 20; TGF- $\beta 1$, Transforming growth factor beta 1 .

Acknowledgment To FAPESP/Fundação de Amparo à Pesquisa do Estado de Sao Paulo for research funding and a studentship. A Canadian Foundation for Innovation (CFI) grant to A.V.P. funded all the equipment used in the intial optimization of these studies.

\section{Compliance with Ethical Standards}

Competing Interests The authors declare that they have no competing interests. 


\section{Appendix}

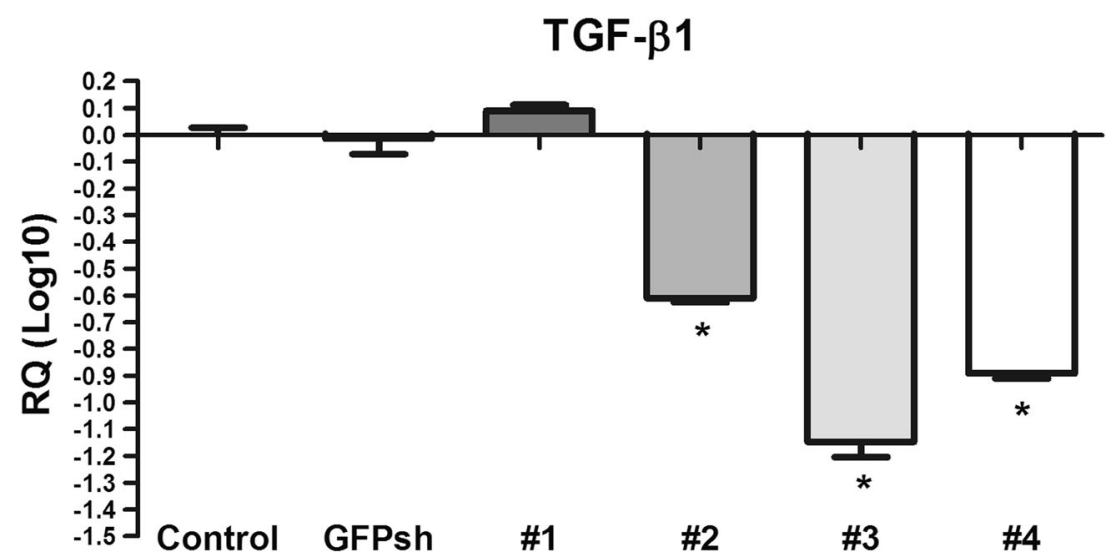

Fig. 10 TGF- $\beta 1$ mRNA expression in cells with TGF- $\beta 1$ knockdown. Analyses of TGF- $\beta 1 \mathrm{mRNA}$ expression in cells with TGF- $\beta 1$ knockdown (TGF- $\beta 1$ sh cells) to select the best sequence to implant into shRNA sequences. Statistically significant differences were determined by ANOVA followed by Bonferroni's test. $* p<0.05$ in comparison with untreated parental cells the animals. The numbers $1,2,3$ and 4 correspond to different TGF- $\beta 1$ body weight of animals in the different treatment groups as a function of time. No statistically significant differences were observed $(p>0.05)$
Fig. 11 Body weight. Average

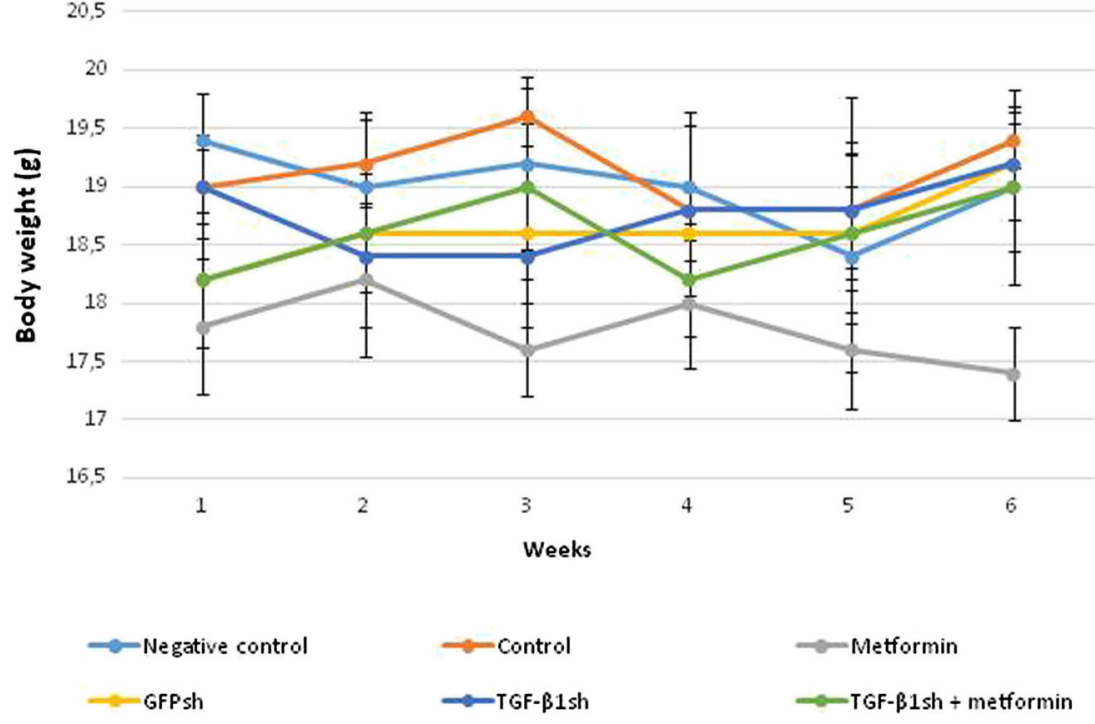

Fig. 12 Glycemia. Glucose levels in the different animal groups as a function of time. No statistically significant differences were observed $(p>0.05)$

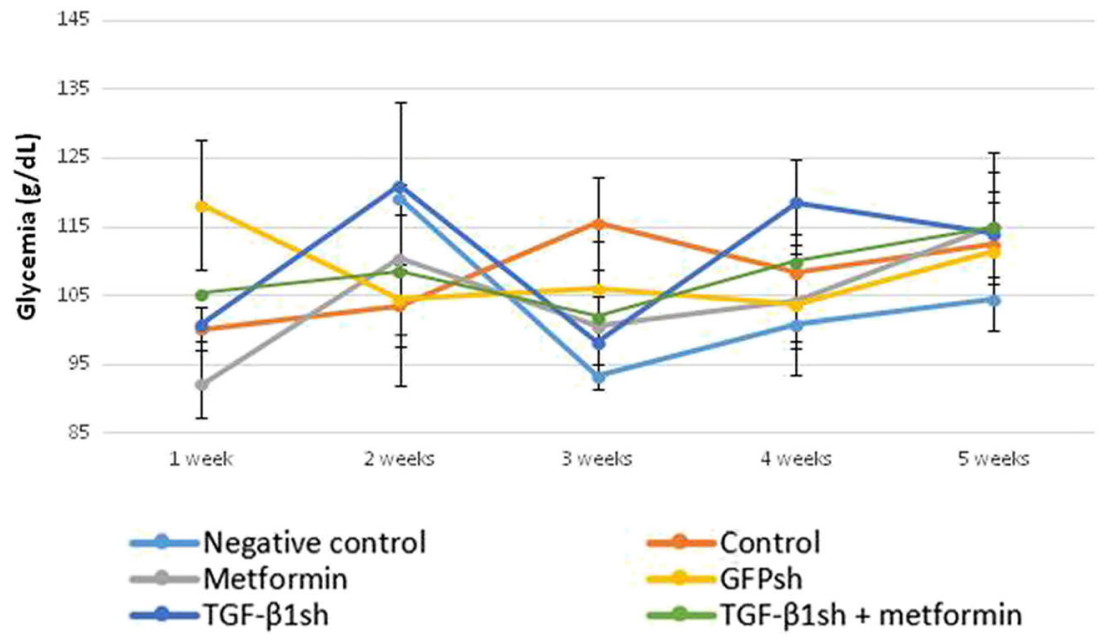


Fig. 13 Tumor volume. Average tumor volume in the different animal groups as a function of time. After one week of tumor cell implantation, the animals received metformin treatment for 4 weeks. Statistically significant differences, verified by ANOVA followed by Bonferroni's test. $* p<0.05$ in comparison to control of untreated parental cells or control of shRNA-expressing cells

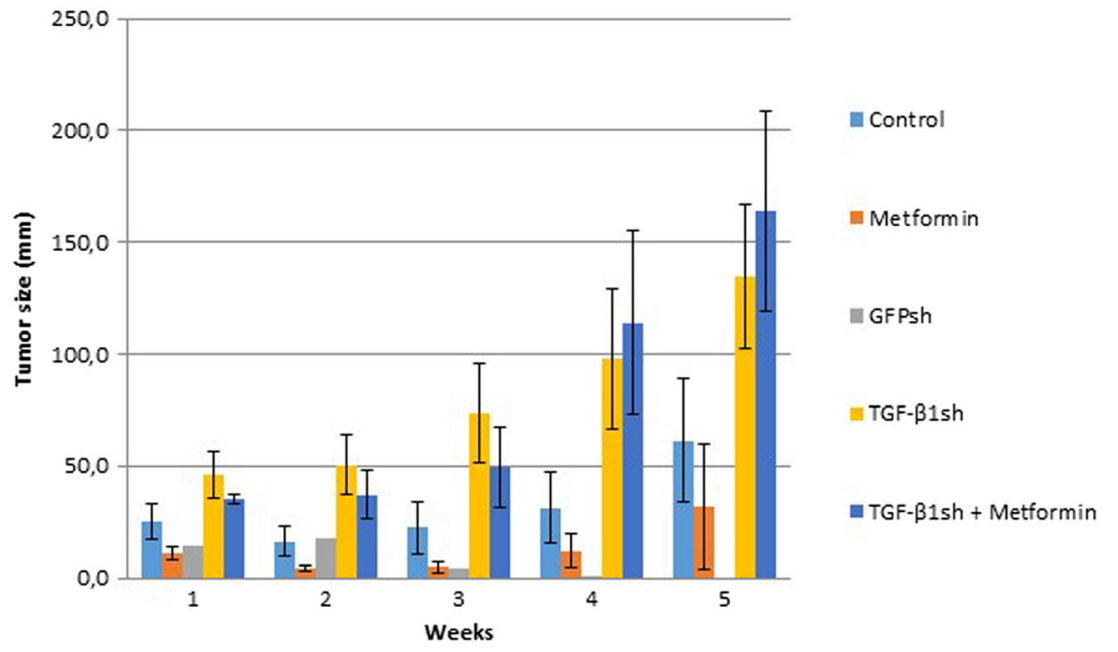

\section{References}

1. Simonetti S, Terracciano L, Zlobec I, Kilic E, Stasio L, Quarto M, et al. Immunophenotyping analysis in invasive micropapillary carcinoma of the breast: role of CD24 and CD44 isoforms expression. Breast. 2012;21:165-70.

2. Prislei S, Martinelli E, Zannoni GF, Petrillo M, Filippetti F, Mariani $\mathrm{M}$, et al. Role and prognostic significance of the epithelialmesenchymal transition factor ZEB2 in ovarian cancer. Oncotarget. 2015.

3. Sigurdsson V, Hilmarsdottir B, Sigmundsdottir H, AJR F, Ringnér $\mathrm{M}$, et al. Endothelial induced EMT in breast epithelial cells with stem cell properties. PLoS One. 2011; doi:10.1371/journal. pone.0023833.

4. Foroni C, Broggini M, Generali D, Damia G. Epithelial-mesenchymal transition and breast cancer: role, molecular mechanisms and clinical impact. Cancer Treat Rev. 2011;38:689-97.

5. Yang J, Weinberg RA. Epithelial-mesenchymal transition: at the crossroads of development and tumor metastasis. Dev Cell. 2008;14:818-29.

6. Wen YC, Lee WJ, Tan P, Yang SF, Hsiao M, Lee LM, et al. By inhibiting snail signaling and miR-23a-3p, osthole suppresses the EMT-mediated metastatic ability in prostate cancer. Oncotarget. 2015.

7. Puisieux A, Brabletz T, Caramel J. Oncogenic roles of EMTinducing transcription factors. Nat Cell Biol. 2014;16:488-94.

8. Bierie B, Moses HL. TGFb: the molecular Jekyll and Hyde of cancer. Nat Rev Cancer. 2006;6:506-20.

9. Ikushima H, Miyazono K. TGFb signalling: a complex web in cancer progression. Nat Rev Cancer. 2010;10:415-24.

10. Wu MY, Hill CS. Tgf-beta superfamily signaling in embryonic development and homeostasis. Dev Cell. 2009;16:329-43.

11. Siegel PM, Shue W, Cardiff RD, et al. Transforming growth factor $h$ signaling impairs Neu-induced mammary tumorigenesis while promoting pulmonary metastasis. Proc Natl Acad Sci U S A. 2003;100:8430-5.

12. Bandyopadhyay A, Agyin J, Wang L, et al. Inhibition of pulmonary and skeletal metastasis by a transforming growth factor-h type I receptor kinase inhibitor. Cancer Res. 2006;66:6714-21.

13. Padua $\mathrm{D}$, Zhang XH, Wang Q, et al. TGFb primes breast tumors for lung metastasis seeding through angiopoietin-like. Cell. 2008;133: 66-77.

14. Reiman JM, Knutson KL, Radisky DC. Immune promotion of epithelial mesenchymal transition and generation of breast cancer stem cells. Cancer Res. 2010;70(8):3005-8.
15. Wang QZ, Lu YH, Jiang N, Diao Y, Xu RA. The asymmetric division and tumorigenesis of stem cells. Chinese journal of cancer. 2010;29:248-53.

16. Mani SA, Guo W, Liao MJ, et al. The epithelial-mesenchymal transition generates cells with properties of stem cells. Cell. 2008;133:704-15.

17. Short JJ, Curiel DT. Oncolytic adenoviruses targeted to cancer stem cells. Mol Cancer Ther. 2009;8:2096-102.

18. Moore LD, Isayeva T, Siegal GP, Ponnazhagan S. Silencing of transforming growth factor- $\beta 1$ in situ by RNA interference for breast cancer: implications for proliferation and migration in vitro and metastasis in vivo. Clin Cancer Res. 2008;14:4961.

19. Zhao X, Zou Y, Gu Q, Zhao G, Gray H, Pfeffer LM, Yue J. Lentiviral vector mediated Claudin1 silencing inhibits epithelial to mesenchymal transition in breast cancer cells. Viruses. 2015;7: 2965-79.

20. Noto H, Goto A, Tsujimoto T, Noda M. Cancer risk in diabetic patients treated with metformin: a systematic review and meta-analysis. PLoS One. 2012;7:33411.

21. Hatoum D, McGowan EM. Recent advances in the use of metformin: can treating diabetes prevent breast cancer? Biomed Res Int. 2015; doi:10.1155/2015/548436. Epub 2015 Mar 19.

22. Camacho L, Dasgupta A, Jiralerspong S. Metformin in breast cancer - an evolving mystery. Breast Cancer Res. 2015;17:88.

23. Barrière G, Tartary M, Rigaud M. Metformin: a rising star to fight the epithelial mesenchymal transition in oncology. Anti Cancer Agents Med Chem. 2013;13:333-40.

24. Queiroz EA, Puukila S, Eichler R, Sampaio SC, Forsyth HL, Lees $\mathrm{SJ}$, et al. Metformin induces apoptosis and cell cycle arrest mediated by oxidative stress, AMPK and FOXO3a in MCF-7 breast cancer cells. PLoS One. 2014;9(5):e98207.

25. Qu C, Zhang W, Zheng G, Zhang Z, Yin J, He Z. Metformin reverses multidrug resistance and epithelial-mesenchymal transition (EMT) via activating AMP-activated protein kinase (AMPK) in human breast cancer cells. Mol Cell Biochem. 2014;386:63-71.

26. Liu Z, Ren L, Liu C, Xia T, Zha X, Wang S. Phenformin induces cell cycle change, apoptosis, and mesenchymal-epithelial transition and regulates the AMPK/mTOR/p70s6k and MAPK/ERK pathways in breast cancer cells. PLoS One. 2015;10(6):e0131207.

27. Hirsch HA, Iliopoulos D, Tsichlis PN, Struhl K. Metformin selectively targets cancer stem cells and acts together with chemotherapy to block tumor growth and prolong remission. Cancer Res. 2009;69:7507-11. 
28. Cufi S, Vazquez-Martin A, Oliveras-Ferraros C, Martin-Castillo B, Joven J, Menendez JA. Metformin against TGFb-induced epithelialto-mesenchymal transition (EMT). Cell Cycle. 2010;9:4461-8.

29. Heale BSE, Soifer HS, Bowers C, Rossi JJ. siRNA target site secondary structure predictions using local stable substructures. Nucleic Acids Res. 2005;33:e30.

30. Stewart SA, Dykxhoorn DM, Palliser D, Mizuno H, Yu EY, An DS, Sabatini DM, Chen ISY, Hahn WC, Sharp PA, Weinberg RA, Novina CD. Lentivirus-delivered stable gene silencing by RNAi in primary cells. RNA. 2003;9:493-501.

31. Bustin SA, Benes V, Garson JA, Hellemans J, Huggett J, Kubista M, Mueller R, Nolan T, Pfaffl MW, Shipley GL, Vandesompele J, Wittwer CT. The MIQE guidelines:minimum information for publication of quantitative real-time PCR experiments. Clin Chem. 2009;55:611-22.

32. Rattan R, Graham RP, et al. Metformin suppresses ovarian cancer growth and metastasis with enhancement of cisplatin cytotoxicity in vivo. Neoplasia. 2011;13:483-91.

33. Wang M, Liu X, Guo J, et al. Inhibition of LSD1 by Pargyline inhibited process of EMT and progression of prostate cancer in vivo. Biochem Biophys Res Commun. 2015;467:310-5.

34. Hwang YP, Jeong HG. Metformin blocks migration and invasion of tumour cells by inhibition of matrix metalloproteinase-9 activation through a calcium and protein kinase Calpha-dependent pathway: phorbol-12-myristate-13-acetate-induced/extracellular signalregulated kinase/activator protein-1. Br J Pharmacol. 2010;160: 1195-211.

35. Cerezo M, Tichet M, Abbe P, et al. Metformin blocks melanoma invasion and metastasis development in AMPK/p53-dependent manner. 2013;12:1605.

36. Zhang J, Shen C, Wang L, Ma Q, Xia P, Qi M, Yang M, Han B. Metformin inhibits epithelial-mesenchymal transition in prostate cancer cells: involvement of the tumor suppressor miR30a and its target gene SOX4. Biochem Biophys Res Commun. 2014;452: 746-52.

37. Saeki K, Watanabe M, Tsuboi M, et al. Anti-tumour effect of metformin in canine mammary gland tumour cells. Vet J. 2015;205: 297-304.

38. Barbieri $\mathrm{F}$, Thellung $\mathrm{S}$, Ratto $\mathrm{A}$, et al. In vitro and in vivo antiproliferative activity of metformin on stem-like cells isolated from spontaneous canine mammary carcinomas: translational implications for human tumors. BMC Cancer. 2015;15:228.

39. Kisfalvi K, Aune M, Sinnett-Smith J, et al. Metformin inhibits the growth of human pancreatic cancer xenografts. Pancreas. 2013;42: 781-5.

40. Burnett JP, Korkaya H, Ouzounova MD, et al. Trastuzumab resistance induces EMT to transform HER2 ${ }^{+} \mathrm{PTEN}^{-}$to a triple negative breast cancer that requires unique treatment options. Sci Rep. 2015;5:15821.33.

41. Pon YL, Zhou HY, Cheung ANY, Ngan HYS, Wong AST. p70 S6 kinase promotes epithelial to mesenchymal transition through snail induction in ovarian cancer cells. Cancer Res. 2008;68:6524-32.

42. Rattan R, Fehmi RA, Munkarah A. Metformin: an emerging new therapeutic option for targeting cancer stem cells and metastasis. J Oncol. 2012;2012:928127.
43. Zarzynska JM. Two faces of TGF-betal in breast cancer. Mediat Inflamm. 2014; doi:10.1155/2014/141747.

44. Siegel PM, Shu W, Cardiff RD, Muller WJ, Massagué J. Transforming growth factor beta signaling impairs Neu-induced mammary tumorigenesis while promoting pulmonary metastasis. Proc Natl Acad Sci U S A. 2003;100:8430-5.

45. Dunning AM, Ellis PD, McBride S, et al. A transforming growth factor $\beta 1$ signal peptide variant increases secretion in vitro and is associated with increased incidence of invasive breast cancer. Cancer Res. 2003;63:2610-5.

46. Bierie B, Moses HL. Transforming growth factor beta (TGF- $\beta$ ) and inflammation in cancer. Cytokine Growth Factor Rev. 2010;21:49-59.

47. Sun $\mathrm{L}, \mathrm{Wu} \mathrm{G}$, Willson JKV, et al. Expression of transforming growth factor $\beta$ type II receptor leads to reduced malignancy in human breast cancer MCF-7 cells. J Biol Chem. 1994;269: 26449-55.

48. Wang J, Sun L, Myeroff L, et al. Demonstration that mutation of the type II transforming growth factor $\beta$ receptor inactivates its tumor suppressor activity in replication error- positive colon carcinoma cells. J Biol Chem. 1995;270:22044-9.

49. Kim SJ, Im YH, Markowitz SD, Bang YJ. Molecular mechanisms of inactivation of TGF- $\beta$ receptors during carcinogenesis. Cytokine Growth Factor Rev. 2000;11:159-68.

50. Lebrun JJ. The dual role of TGF in human cancer: from tumor suppression to cancer. Metastasis. 2012;2012:28.

51. WANG J, Qiuling Gao Q, Decui Wang D, Wang Z, Hu C. Metformin inhibits growth of lung adenocarcinoma cells by inducing apoptosis via the mitochondria-mediated pathway. Oncol Lett. 2015;10:1343-9.

52. Tsutsumi Y, Nomiyama T, Kawanami T, et al. Combined treatment with Exendin-4 and metformin attenuates prostate cancer growth. PLoS One. 2015;10:e0139709.

53. Lipner MB, Marayati R, Deng Y, et al. Metformin treatment does not inhibit growth of pancreatic cancer patient-derived xenografts. PLoS One. 2016;11:e0147113.

54. Zhang Y, Guan M, Zheng Z, Zhang Q, Gao F, Xue Y. Effects of metformin on $\mathrm{CD} 133+$ colorectal cancer cells in diabetic patients. PLoS One. 2013;8:81264.

55. Cohn A, Lahn MM, Williams KE, Cleverly AL, et al. A phase I dose-escalation study to a predefined dose of a transforming growth factor- $\beta 1$ monoclonal antibody (T $\beta \mathrm{M} 1)$ in patients with metastatic cancer. Int J Oncol. 2014;45:2221-31.

56. Rice LM, Padilla CM, McLaughlin SR, Mathes A, et al. Fresolimumab treatment decreases biomarkers and improves clinical symptoms in systemic sclerosis patients. J Clin Invest. 2015;125:2795-807.

57. Wang D, Lu P, Zhang H, et al. Oct-4 and Nanog promote the epithelial-mesenchymal transition of breast cancer stem cells and are associated with poor prognosis in breast cancer patients. Oncotarget. 2014;5:10803-15.

58. Davis FM, Azimi I, Faville RA, et al. Induction of epithelialmesenchymal transition (EMT) in breast cancer cells is calcium signal dependent. Oncogene. 2014;33:2307-16. 